\title{
Nursing Students' Readiness for Self-Directed Learning and Its Effect on Learning Outcome in South-West Nigeria
}

\author{
Guobadia Pauline Ojekou*, Funmilayo A. Okanlawon \\ Department of Nursing, University of Ibadan, Oyo State, Ibadan, Nigeria \\ Email: *paulineguobadia@yahoo.com
}

How to cite this paper: Ojekou, G.P. and Okanlawon, F.A. (2019) Nursing Students' Readiness for Self-Directed Learning and Its Effect on Learning Outcome in South-West Nigeria. Open Journal of Nursing, 9, 586-601.

https://doi.org/10.4236/ojn.2019.96048

Received: March 29, 2019

Accepted: June 27, 2019

Published: June 30, 2019

Copyright () 2019 by author(s) and Scientific Research Publishing Inc. This work is licensed under the Creative Commons Attribution International License (CC BY 4.0).

http://creativecommons.org/licenses/by/4.0/

\begin{abstract}
Self-directed learning (SDL) uses diverse learning resources to solve identified problems in learning. Nursing is a lifelong learning profession and SDL is a valuable skill to remain relevant and productive professionals. Nursing students are expected to embrace SDL and develop these skills. However, there has been no evidence of this innovative process in South-West Nigeria. This study seeks to evaluate nursing students' readiness for SDL and its effect on learning outcome. This quasi-experimental study purposively utilized 229 nursing students as participants. Baseline (P1) data was collected using Gugliemino's SDL readiness scale (SDLRS) and a validated-structured questionnaire. Participants had a pre-test to assess knowledge at P1 followed by 6 weeks interaction using SDL on selected topics in Medical-surgical nursing and the same test at post-intervention (P2). Using a 50-point scale, knowledge was categorized as good $\geq 25$ and poor $<25$ and SDLRS on a 290-point scale was categorized as below average 5 - 201, average $202-226$ and above average 227 - 290. Descriptive statistics, Chi-square test, t-test and linear regression analysis were used for analysis at $\mathrm{p}=0.05$. Nursing students' SDLRS was average; mean $=203 \pm 23$.0. A significant difference exists between nursing students with good knowledge at P1 and P2. At P1, 39.2\% had good knowledge, mean $=22.2 \pm 6.3$, and $90.1 \%$ at $\mathrm{P} 2$, mean $=30.6 \pm 5.4, \mathrm{p}<0.05$ also a significant relationship exist between SDLR and learning outcome at P2; $\mathrm{p}<0.05$. With the nursing students' average SDL readiness level having a significant effect on learning outcome. Nursing training institutions should provide necessary resources to embrace SDL as a main-line teaching method to ensure competent life-long professionals.
\end{abstract}

\section{Keywords}

Effects, Self-Directed Learning Readiness, Resources, Learning Outcome, Nursing Students 


\section{Introduction}

Self-directed learning (SDL) has become a focus for nursing education in the past few decades due to the complexity and changes in nursing profession development [1].

Recently, health-related training programmes, nursing inclusive are undergoing innovative evidence-based changes in many parts of the world [2]. The ability of an individual to be a self-directed learner is regarded as a valuable skill in schools and among different professionals [3]. Helping students get more out of their search for knowledge by being self-directed is a major goal of teaching and training institutions [4]. SDL has been defined as a process in which learners take the initiative in planning, implementing, and evaluating their own learning needs and outcomes, with or without the help of others (Knowles, 1975). When self-directed learning is introduced as a supplement to the traditional learning approach, it provides learners with a greater opportunity to reach their own potentials [5] and educators will be able to keep students engaged and active participants in the teaching-learning activities thereby enhancing learning.

As nursing knowledge and skills advance, it may be difficult to pass on to students all that is needed to make them proficient nurses in three years through traditional didactic lectures. This brings about an increasing emphasis on student-centered learning as opposed to traditional didactic lectures [6].

The structure and the orientation of educational designs in the general nursing curriculum in Nigeria emphasize the importance of utilizing diverse teaching strategies in teaching nursing students. These designs that would facilitate learners' independence of teachers are yet to be fully adopted in Nigerian schools of nursing due factors we do not know. It is observed that students even at post secondary institutions expect every lecturer to give lecture notes or handouts which is not good enough for a life-long learning profession like nursing.

The consequences of this are that nurses who are unable to guide their own learning may not be equipped with current knowledge and skills that are essential in tackling the complex and changing nature of the health care field. In order to meet up with these challenges, nursing education programmes need to place a greater emphasis on adult education, in particular SDL, believing it is useful for learners to be given the skills to effectively search for, discover, examine and apply new knowledge independently. These skills are individualized and can be affected by attitude, ability, and personality characteristics of the learner. The readiness for self-directed learning (RSDL) depends on personal attributes as well as the curriculum adopted by institutions [7].

In literature for now, there is no evidence of a similar study among nursing students in Nigeria but there were similar studies among nursing students in other developed nations. A study on self-directed learning readiness and learning styles among Saudi undergraduate nursing students revealed that their total mean score of self-directed learning readiness was $159.6^{(2)}, 154.72$ among Chinese baccalaureate nursing students [8] and 150.55 among Australian under- 
graduate nursing students [9] respectively. The researchers intend to discover the extent to which adult learners in particular nursing students in Nigeria are ready to be self-directed learners and its effect on learning outcome.

\section{Methodology}

This study purposively selected 229, 200 or 300 level nursing students from five randomly selected schools of nursing out of 22 accredited schools of nursing in South-West Nigeria by balloting to take part in a quasi-experimental study investigating nursing students' readiness for SDL and its effect on learning outcome. In South-West Nigeria, there is no evidence of publications relating to nursing students' readiness for SDL and its effect on learning outcome.

\subsection{Study Population}

The study population included all the second or third year Nursing students undergoing training in the five selected Schools of Nursing in South-West Nigeria. This population is selected for the study based on the year the nursing students are introduced to lectures on Medical-Surgical nursing course during their nursing training. This is to ensure that there is no form of contamination whatsoever.

\subsection{Study Design}

The study is a pre-test post-test one group quasi-experimental design which purposively selected 229 nursing students from five different schools of nursing training within South-West Nigeria to assess nursing students' readiness for self-directed learning and its effect on learning outcome.

\subsection{Sample Size Determination}

The sample size for the study was determined using the sample size formula below [10]

$$
n=\frac{t^{2} \times P(1-P)}{m^{2}}
$$

with a calculated sample size of 178 .

\subsection{Sampling Technique}

A purposive sampling technique was used to select the South-West Zone of Nigeria in order to have schools that are homogenously related. The South-West Region of Nigeria is one of the six geo-political regions in the country. It has six states; it is majorly a Yoruba speaking area, although there are different dialects even within the same state. The area is blessed with a lot of schools both at primary, secondary and tertiary levels among the post-secondary schools (tertiary schools) are twenty-two [22] accredited schools of nursing offering Basic Nursing training under the different arms of Government; federal government, state government and different religious organizations. A simple random sampling 
technique (balloting) was used to select three states from the six states in the zone. All the sixteen [16] accredited Schools of Nursing within the three [3] states selected were listed out and five [5] Schools of Nursing were selected by balloting.

From each selected school of nursing, the second or third year nursing students were purposively selected depending on the year the students are introduced to Medical-Surgical nursing during their training. The calculated sampling size was 178 . Since 178 is the minimum sample size that can be studied the researchers decided to increase the power of significance by including all the second or third year nursing students in the sample frame which is 229 altogether. This is because determining the optimal sample size for a study assures an adequate power to detect statistical significance and that power proportionately increases as the sample size for study increases [11]. The students also had a lot to benefit from the intervention hence all the students who were available and willing to participate in the study were included.

\subsection{Exclusion Criteria}

Post basic students offering distant learning programmes in nursing as they are already trained.

Direct entry students who are already Registered Nurses.

Students in the first year of training as they offer mostly general courses and do not have medical-surgical nursing in their curriculum for the first year, students in their fourth and fifth years of training as they have been receiving lectures in medical-surgical nursing and would have had lectures and be familiar with the selected topics.

\subsection{Ethical Consideration}

The study was approved by the University of Ibadan/University College Hospital Ethical Review/Ethics Committee. All ethical issues were strictly adhered to, the research purpose, the intervention and procedure for data collection was explained to the participants. Written consent was obtained from each participant. Participation was entirely voluntary, confidential and anonymous. UI/UCH Ethics Committee assigned number: UI/EC/14/0353.

\subsection{Instrument for Data Collection}

The self-developed questionnaire was used to cover demographic characteristics, Readiness for Self-Directed Learning (SDL) Scale was used with permission from Gugliemino (2008) to assess the Self-Directed Learning Readiness level of the nursing students. It is composed of 58 items with responses on a five-point $\mathrm{Li}$ kert scale. It is designed to assess individual attitudes, values, skills and personality characteristics indicative of self-direction in learning. An internal reliability of 0.87 (Cronbach alpha) was reported for the 58-item version of the instrument. Most published studies on populations over twenty years old report reliability 
figures ranging from 0.72 to 0.92 [12].

The average score for adults completing the SDLRS-A questionnaire is 214 and the standard deviation is 25.59. The SDLRS/LPA measures your current level of readiness for self-directed learning. On a 290-ponit scale the SDLRS was categorized as below average 58 - 201, average 202 - 226 and above average 227 290.

Persons with high SDLRS scores usually prefer to determine their learning needs and plan and implement their own learning.

Persons with average SDLRS scores are more likely to be successful in more independent situations, but are not fully comfortable with handling the entire process of identifying their learning needs and planning and implementing the learning.

Persons with below average SDLRS scores usually prefer very structured learning options such as lecture and traditional classroom settings.

The researchers visited the students two weeks before the commencement of the study for personal introduction and familiarization.

The Self-Directed Learning Readiness Scale was administered personally by the researchers to each participant during this first encounter. Responses were coded with the last four digits of participants' phone numbers for identification purpose. The score for the responses was summed up to determine the nursing students' readiness for self-directed learning at baseline and a guide to modify the adopted SDL module for interaction.

Pretest on Medical-Surgical Nursing course covering six topics selected to measure learning outcomes was administered at baseline.

The objectives for the learning interaction were drawn with the involvement of the students and the already modified teaching module was presented to them.

The modalities of the self-directed learning interaction were discussed and selection of the learning strategies the students utilized for interaction was done.

The nursing students had a two-hour interaction three times a week for six weeks using the selected self-directed learning strategies. Students were shared into five groups depending on their self-directed learning readiness scores to achieve a good mix of students in each group. Different topics were allocated to each group and the last topic was given as an individual assignment. The assignments were collected and scored by the end of the fifth week of interaction. By the end of the sixth week, all the five groups have presented the topics allocated to their group as a seminar presentation in class. The same test items administered at baseline were re-administered as a final learning outcome post-test on the same topics in the seventh week. The learning outcome test was scored and the scores recorded in percentile for comparison with the pre-test scores. Only 212 students completed the study to post-intervention and analyzed.

Data were analyzed using SPSS version 16, Chi-square, t-test and regression analysis were used to measure associations at $\mathrm{p}=0.05$. Findings are shown in 
Tables 1-7.

\section{Results}

The results are presented based on the objectives and hypotheses of the study.

Table 1 shows that among the 212 nursing students that participated in the study to post-intervention, there were only 21 (9.9\%) male nursing students and 191 (90.1\%) females, 93 (43.9\%) below 20 years, 51 (24.1\%) between $21-22$ years while $68(32.1 \%)$ above 22 years; mean age $28.9 \pm 3.1$. Educational qualification attained before embarking on nursing training revealed that 194 (91.5\%) had only secondary school training while only $18(8.5 \%)$ had other post-secondary school qualification.

Table 1. Socio-demographic characteristics of the nursing students.

\begin{tabular}{ccccc}
\hline Variable & Frequencies & Percent & $\begin{array}{c}\text { Valid } \\
\text { percent }\end{array}$ & $\begin{array}{c}\text { Cumulative } \\
\text { percent }\end{array}$ \\
\hline Gender & & & & \\
Male & 21 & 9.9 & 9.9 & 9.9 \\
Female & 191 & 90.1 & 90.1 & 100 \\
& & & & \\
Age Group & & & & \\
$<20$ years & 93 & 43.9 & 43.9 & 43.9 \\
$21-22$ years & 51 & 24.1 & 24.1 & 67.9 \\
$\geq 22$ years & 68 & 32.1 & 32.1 & 100 \\
Min $=17$, Max $=34$, & & & & \\
Mean Age 28.9 \pm 3.1 & & & & \\
& & & & \\
Educational qualification attained & 194 & 91.5 & 91.5 & 91.5 \\
Secondary & 18 & 8.5 & 8.5 & 100 \\
Others & & & & \\
\hline
\end{tabular}

Table 2. Level of readiness for self-directed learning of nursing students in South-West Nigeria.

\begin{tabular}{ccccc}
\hline Score group & Frequencies & Percent \% & Valid percent & Cumulative percent \\
\hline below average & 96 & 45.3 & 45.3 & 45.3 \\
average & 85 & 40.1 & 40.1 & 85.4 \\
above average & 31 & 14.6 & 14.6 & 100.0 \\
Total & 212 & 100.0 & 100.0 & \\
\hline
\end{tabular}

Table 3. Interpretation of the SDLRS-A/LPA Score.

\begin{tabular}{cc}
\hline$S D L R S-A$ score & Readiness for self-directed learning \\
\hline $58-201$ & Below average \\
$202-226$ & Average \\
$227-290$ & Above average \\
\hline
\end{tabular}

(Guglielmino, 2008)* [12], *: Used with permission from Guglielmino, 2008. 
Table 4. Self-Directed Learning Readiness Score (SDLRS) of nursing students at pre-intervention and post-intervention.

\begin{tabular}{ccccccccc}
\hline \multicolumn{3}{c}{ Pre-Intervention } & \multicolumn{5}{c}{ Post-Intervention } \\
\hline $\begin{array}{c}\text { Variable } \\
\text { SDLRS }\end{array}$ & $\begin{array}{c}\text { Score } \\
\text { Group }\end{array}$ & N\% & $\mathrm{X}^{2}$ & P-value & $\begin{array}{c}\text { Nursing } \\
\text { Students }\end{array}$ & N\% & $\mathrm{X}^{2}$ & P-value \\
\hline $\begin{array}{c}\text { Below } \\
\text { Average }\end{array}$ & 96 & 45.3 & & & 5 & 2.4 & & \\
Average & 85 & 40.1 & 6.184 & 0.065 & 28 & 13.2 & 119.50 & 0.005 \\
$\begin{array}{c}\text { Above } \\
\text { Average }\end{array}$ & 31 & 14.6 & & & 179 & 84.4 & & \\
Total & 212 & 100 & & & 212 & 100 & \\
\hline
\end{tabular}

Table 5. Showing difference in mean values of the nursing students' self-directed learning readiness score at pre-intervention and post-intervention.

\begin{tabular}{|c|c|c|c|c|c|c|c|}
\hline \multicolumn{3}{|c|}{ Baseline } & \multicolumn{5}{|c|}{ Post Intervention } \\
\hline Variable & $\mathbf{N}$ & $\begin{array}{c}\text { Baseline } \\
\text { Mean } \pm \text { SD }\end{array}$ & $t$ & $\begin{array}{c}\text { P-value } \\
\text { Sig (2tailed) }\end{array}$ & $\begin{array}{c}\text { Post } \\
\text { intervention } \\
\text { Mean } \pm \text { SD }\end{array}$ & $\mathbf{t}$ & $\begin{array}{c}\text { P-value } \\
\text { Sig (2 } \\
\text { tailed) }\end{array}$ \\
\hline $\begin{array}{l}\text { SDLRS of } \\
\text { nursing } \\
\text { students }\end{array}$ & 212 & $203 \pm 23.0$ & -1.22 & 0.224 & $245.0 \pm 12.25$ & 0.609 & 0.005 \\
\hline
\end{tabular}

Minimum value $=122$, Maximum value $=251$.

Table 6. Learning outcome of nursing students on medical-surgical nursing at pre- and post-intervention.

\begin{tabular}{ccccc}
\hline Learning outcome & N & Minimum score & Maximum Score & Mean Score \\
\hline Pre-test & 212 & 3 & 35 & $22.16 \pm 6.3$ \\
Post-test & 212 & 34 & 90 & $30.60 \pm 5.4$ \\
\hline
\end{tabular}

Table 7. Table of multiple regression analysis showing effect of readiness for SDL on learning outcome of nursing students at pre- and post-intervention.

(a)

\begin{tabular}{ccccc}
\hline \multicolumn{4}{c}{ Dependent variable: Learning Outcome at Post-Intervention } \\
\hline SDLR Score group & Frequencies & $\boldsymbol{\beta}$ & $\boldsymbol{t}$ & $\mathrm{p}$-value \\
\hline Constant & & & 12.909 & 0.000 \\
Learning outcome at baseline & & 0.430 & 8.552 & 0.000 \\
Group & & -5.147 & -10.567 & 0.000 \\
Below average & 5 & 0.135 & 0.457 & 0.648 \\
Average & 28 & -7.127 & -9.690 & 0.005 \\
Above average & 179 & -6.116 & -8.018 & 0.001 \\
Total & 212 & & & \\
\hline
\end{tabular}

(b)

\begin{tabular}{cccccc}
\hline Model & SS & df & MS & F & P-value \\
\hline Constant & 1687.639 & 4 & 337.528 & 37.626 & 0.000 \\
Residual & 1426.337 & 207 & 8.971 & & \\
Total & 3113.976 & 211 & & & \\
\hline
\end{tabular}

$\mathrm{R}^{2}=0.542\left(\right.$ Adjusted $\left.\mathrm{R}^{2}=0.528\right)$. 
had only secondary school training while only $18(8.5 \%)$ had other post-secondary school qualifications.

The level of readiness for self-directed learning of nursing students in South-West Nigeria was overall average with a mean value of $203 \pm 23.0$. Ninety six (96: $45.3 \%)$ were below average, 85 (40.1\%) average and 31 (14.6\%) were above average.

- Used with permission from Guglielmino, 2008.

Table 4 shows the difference in the nursing students' readiness for self-directed learning at pre-intervention and post-intervention. At pre-intervention $\mathrm{p}$-value $=$ 0.065 compared to post-intervention $\mathrm{p}$-value $=0.005$. There is a significant difference.

The nursing students' readiness for SDL in Nigeria was average with a minimum value of 122 , maximum value; 251 with a mean value of $203 \pm 23.0$ at pre-intervention and $245.0 \pm 12.25$ at post-intervention which reveals a significant difference $\mathrm{p}=0.005$.

The nursing students had some knowledge of medical-surgical nursing at baseline with a mean score of $22.16 \pm 6.3$ and a much improved knowledge at post-intervention, mean score $30.60 \pm 5.4$.

The table of multiple linear regression analysis above shows effect of readiness for SDL on learning outcome of nursing students at baseline and post-intervention revealed that there is a significant difference in learning outcome at baseline and post-intervention $\mathrm{p}<0.001$. Those who scored below average readiness for SDL at post-intervention did not have any significant effect on learning outcome $\mathrm{p}>$ 0.05 but those with average and above-average scores had a significant effect on learning outcome $\mathrm{p} \geq 0.001$.

\section{Discussion}

This study was carried out to evaluate nursing students' readiness for SDL and its effect on learning outcome in South-West Nigeria. The study revealed that among the 212 nursing students that participated in the study to post-intervention, there were only 21 (9.9\%) male nursing students (Table 1). This shows that in Nigeria just like in other countries, nursing is a female-dominated profession. The feminine nature of nursing has been so prevailing, that the caring image of the profession has been used to symbolize the epitome of femininity [13]. In Canada and the United States, only 5\% of nurses were men [14] [15]. In England and Ireland men also represented $10 \%$ and $4 \%$ of registered nurses (RNs), respectively [16] [17]. In 2006 only about $23 \%$ of nurses in Iran were men [18].

Age distribution of the nursing students showed a mean age of $28.9 \pm 3.1$ (Table 1) indicating that the nursing students were mostly young adults in their twenties who may still need the assistance of a teacher to achieve their learning needs, and this is a very active age when students occupy themselves with a lot of social activities and hardly have enough time for long sitting in search of educational materials. This is seen as $194(91.5 \%)$ of the respondents stated that they 
started nursing training immediately after they left secondary school (Table 1). This is contrary to Freedman's [19] assertions that the adult learner is someone who is motivated enough to want to pine for further education at the end of a working day or is required to come to a program for certification after identifying a learning need. Self-directed learning (SDL) is seen as an adult learning strategy and nursing students are expected to possess SDL skills to pursue lifelong learning. Knowles [20] opined that as adults mature, they naturally move towards self-direction in their learning. The nursing students' readiness for SDL in Nigeria was average but the findings were higher than most findings reported by other researchers from more developed countries. The minimum value for the nursing students' readiness for SDL was 122, maximum value; 251 with a mean value of $203 \pm 23.0$. This average self-directed readiness score is slightly higher than the findings reported from previous studies in other countries (Table 2); a study on self-directed learning readiness and learning styles among Saudi undergraduate nursing students revealed that their total mean score of self-directed learning readiness was $159.6^{(2)}, 154.72$ among Chinese baccalaureate nursing students [8] and 150.55 among Australian undergraduate nursing students [9].

The nursing students had some level of knowledge of medical-surgical nursing at baseline. At baseline, the minimum knowledge score was $3(6 \%)$ while the maximum score was $35(70 \%)$. At post-intervention, the minimum knowledge score was 17 (34\%) and the maximum score; 45 (90\%) (Table 6). This could be related to the fact that nursing training is a programme which combines a period of classroom instructions with clinical experience before certification as professional nurses. Caring for patients is considered a focus of further learning for healthcare personnel both during training and after certification in order to increase their knowledge, skills and professional development. The Nursing and Midwifery Council of Nigeria in her Curriculum for the General Nursing training programme makes clinical posting for a stipulated number of weeks a compulsory requirement before certification as a professional nurse. It is believed that during the clinical posting, the nursing students must have come across some of the selected disease conditions as they care for patients and the few who are SDL inclined must have gone out on their own to gather information and learn about the disease condition even though they have never been taught as a lecturer in class. This is in harmony with Nokdee's [21] declarations that caring for patients can be the focus of further learning for healthcare personnel even while in training in order to increase their knowledge, skills and professional development. Also Dunn and Burnett [22] asserted that Clinical experience has always been an integral part of nursing education. It prepares student nurses to be able of "doing" as well as "knowing" the clinical principles in practice. The clinical practice stimulates students to use their critical thinking skills for problem solving. In addition, it may be due to the fact that the nursing students are going through a competitive training under the same conditions which made them develop their SDL abilities to seek for additional educational information 
on their own. The study showed that among the nursing students in South-West Nigeria, (Table 7) there was a significant relationship between readiness for self-directed learning and learning outcome in Medical-Surgical nursing. Using multiple regression analysis, there was a significant difference between learning outcome at baseline and at post-intervention, $\mathrm{p}=0.001<0.05$ at baseline and a significant relationship between nursing students readiness for SDL and learning outcome at post-intervention, $\mathrm{P}=0.005<0.05$. This was as a result of the SDL intervention on the nursing students and it is in agreement with the findings and declarations of Horng [23] who carried out a study on the relationship between self-directed learning readiness and learning achievements of the students in National Open University in Taiwan and came up with a positive relationship.

\section{Conclusion}

In conclusion, this study has been able to discover that readiness for SDL has a significant effect on learning outcome among nursing students in South-West Nigeria. Also SDL significantly improved learning outcome at post-intervention.

\section{Recommendations}

- Nurse educators should periodically assess the self-directed learning readiness level of their students and assist learners to understand their own pattern of learning.

- Teachers of nursing programmes should see the need to work with their students as adult learners and search for educating information together.

- Teachers of nursing programmes should adopt new forms of strategies to promote teaching for better understanding and bring about an active student-centered explicit approach to teaching and learning.

- Institutions of learning should provide facilities that will promote self-directed learning in schools of nursing and make them accessible to nursing students.

- The Nursing and Midwifery Council of Nigeria should ensure that self-directed learning is fully adopted as a major teaching/learning strategy in schools of nursing.

\section{Limitations of the Study}

The study was carried out only among second or third year nursing students in five randomly selected nursing training institutions in South-Western Nigeria utilizing a quasi-experimental design since the participants cannot be totally controlled. Though the sample represented nursing students generally as they have similar characteristics with all nursing students in Nigeria, a study with a larger sample size and in other Geo-political zones of the country would have been more generalizable considering the ethnic and cultural differences.

\section{Acknowledgements}

Special thanks to participants, Gugliemino Associates and the institutions used 
for the study. The study is part of a $\mathrm{PhD}$ thesis.

\section{Conflicts of Interest}

The authors declare no conflicts of interest regarding the publication of this paper.

\section{References}

[1] El-Gilany, A.-H. and Abusaad, F.S. (2013) Self-Directed Learning Readiness and Learning Styles among Saudi Undergraduate Nursing Students. Nurse Education Today, 33, 1040-1044. https://doi.org/10.1016/j.nedt.2012.05.003

[2] Anyaehie, U.S.B., Nwobodo, E., Oze, G., Nwagha, U.I., Orizu, I., Okeke, T. and Anyanwu, G.E. (2011) Medical Students' Evaluation of Physiology Learning Environments in Two Nigerian Medical Schools. Advances in Physiologycal Education, 35, 146-148. https://doi.org/10.1152/advan.00106.2010

[3] Chou, P.-N. (2012) Effect of Students' Self-Directed Learning Abilities on Online Learning Outcomes: Two Exploratory Experiments in Electronic Engineering. International Journal of Humanities and Social Science, 2, 172-179.

[4] Edmondson, D.R., Boyer, S.L. and Artis, A.B. (2012) Self-Directed Learning: A Meta-Analytic Review of Adult Learning Constructs. International Journal of Education Research, 7, 40-48.

[5] Boyer, S.L., Edmondson, D.R. and Artis, A. (2011) A Meta-Analytic Review of Self-Directed Learning on Key Sales Constructs. National Conference of Sales Management, Orlando, FL, 2011, 1-8.

[6] Nwobodo, E.D., Anyaehie, U.B., Nwobodo, N., Awiwa, C., Ofoegbu, E., Okonkwo, C., Aligekwe, C. and Burdick, B. (2009) Students' Performance and Perception of Neurophysiology: Feedback for Innovative Curricular Reform in a Nigerian Medical School. Nigerian Journal of Physiological Sciences, 24, 63-66. https://doi.org/10.4314/njps.v24i1.46385

[7] Abraham, R.R., Fisher, M., Kamath, A., Izzati, T.A., Nabila, S. and Atikah, N.N. (2011) Exploring First-Year Undergraduate Medical Students' Self-Directed Learning Readiness to Physiology. Advance in Physiological Education, 35, 393-395. https://doi.org/10.1152/advan.00011.2011

[8] Yuan, H.B., Williams, B.A., Fang, J.B. and Pang, D. (2012) Chinese Baccalaureate Nursing Students' Readiness for Self-Directed Learning. Nurse Education Today, 32, 427-431. https://doi.org/10.1016/j.nedt.2011.03.005

[9] Fisher, M.J. and King, J. (2010) The Self-Directed Learning Readiness Scale for Nursing Education Revised: A Confirmatory Factor Analysis. Nurse Education Today, 30, 44-48. https://doi.org/10.1016/j.nedt.2009.05.020

[10] Smith, S.M. (2013) "Determining Sample Size: How to Ensure You Get the Correct Sample Size | Qualtrics”. Qualtrics Retrieved 15 November 2016. https://www.qualtrics.com

[11] Suresh, K.P. and Chandrashekara, S. (2012) Sample Size Estimation and Power Analysis for Clinical Research Studies. Journal of Human Reproductive Science, 5, 7-13. https://doi.org/10.4103/0974-1208.97779

[12] Guglielmino, L.M. (2008) Why Self-Directed Learning? International Journal of Self-Directed Learning, 5, 1-60.

[13] O’Lynn, C.E. (2004) Gender-Based Barriers for Male Students in Nursing Education Programs: Prevalence and Perceived Importance. Journal Nursing Education, 43, 
229-236.

[14] Meadus, R.J. and Twomey, J.C. (2011) Men Student Nurses: The Nursing Education Experience. Nursing Forum, 46, 269-279. https://doi.org/10.1111/j.1744-6198.2011.00239.x

[15] Mullan, B. and Harrison, J. (2008) Male and Female Nursing Applicants' Attitudes and Expectations towards Their Future Careers in Nursing. Journal of Research in Nursing, 13, 527-539.

[16] Fisher, M.J. (2009) "Being a Chameleon": Labour Processes of Male Nurses Performing Bodywork. Journal of Advanced Nursing, 65, 2668-2677. https://doi.org/10.1111/j.1365-2648.2009.05120.x

[17] Keogh, B. and O'Lynn, C. (2007) Male Nurses' Experiences of Gender Barriers: Irish and American Perspectives. Journal of Nursing Education, 32, 256-259. https://doi.org/10.1097/01.NNE.0000299478.64809.82

[18] Khosravi, A., Najafi, F., Rahbar, M., Motlagh, M. and Kabir, M. (2009) Health Profile Indicators in IRI, Center for Health Network Development and Health Promotion. Publication of $\mathrm{MOH}$, Deputy for Health, Tehran.

[19] Freedman, J. (1985) Reflections of a Teacher of Adults. New Directions for Adult and Continuing Education, 1985, 97-102. https://doi.org/10.1002/ace.36719852611

[20] Knowles, M.S. (1980) The Modern Practice of Adult Education: From Pedagogy to Andragogy. 2nd Edition, Cambridge University Press, New York.

[21] Nokdee, S. (2007) Self-Directed Learning among Thai Nurses in Clinical Practice. School of Education, Faculty of Art, Education and Human Development, Victoria University, Melbourne.

[22] Dunn, S.V. and Burnett, P. (1995) The Development of a Clinical Learning Environment Scale. Journal of Advanced Nursing, 22, 1166-1173.

https://doi.org/10.1111/j.1365-2648.1995.tb03119.x

[23] Horng, S.C. (1995) A Study on the Relationship between Self-Directed Learning Readiness and Learning Achievement of the Students in National Open University. The National Taiwan Normal University, Taipei. 


\section{Appendix 1: Questionnaire}

\section{Nursing Students' Readiness for Self-Directed Learning and Its Effect on Learning Outcome in South-West Nigeria}

\section{Learning Preference Assessment}

Dear respondents,

I am Pauline GUOBADIA, a Ph.D student from the Department of Nursing, College of Medicine, University of Ibadan. I am conducting a study on nursing students' readiness for self-directed learning and its effect on learning outcome in south-west nigeria.

I am writing to invite you to participate in this research being undertaken as part of my $\mathrm{PhD}$ studies. I am moving round to learn about the adoption of methods of learning that would facilitate learners' independence of teachers in Nigerian schools of nursing. The purpose of the study is to assess the degree of readiness for self-directed learning of nursing students' using the self-directed learning strategies readiness scale as well as to find out the effect of the readiness of the student nurses learning outcome.

Participation in this study is voluntary; one can withdraw from the study at any time without any penalty whatsoever. This is purely an academic exercise and all information you give shall be kept confidential. You do not need to write your name on the Learning Preference Assessment (LPA) but will be required to write the last four digits of your GSM number for ease of analysis and comparing findings. I implore you therefore to be honest while answering my questions. The LPA asks questions about your learning preferences and attitudes towards learning. There is no right or wrong answer. Thank you

Section A: Demographic data

Instruction: Please kindly tick the option most applicable in the box provided.

1) Name of school of Nursing: (Please Specify)

2) Last four Digits of GSM No: (Please Specify)

3) Gender: (a) Male $\square \quad$ (b) Female $\square$

4) Age last birthday: (Please Specify)

5) Type of secondary School attended:
(a) Public secondary school $\square$
(b) Federal secondary school $\square$
(c) Mission secondary school $\square$
(d) Private secondary school $\square$
6) Educational qualification attained: (a) secondary school $\square$
(b) Others, (please specify) $\square$

7) Year in present programme: (Please Specify)

8) Do you have any clinical experience? (a) Yes $\square \quad$ (b) No $\square$

9) If yes to question 8 above, how many months clinical experience have you had? Please specify

Section B: Learning preferences and attitudes towards learning

Instructions: Please complete the LPA at one sitting. It should take no more than 30 minutes. If you leave the site before completing the assessment, you will need to begin again. 
After reading each item, please tick on the number of the response that best describes your feelings, beliefs, skills, or actions.

1) Almost never true of me: I hardly ever feel this way.

2) Not often true of me: I feel this way less than half the time.

3) Sometimes true of me: I feel this way about half the time.

4) Usually true of me: I feel this way more than half the time.

5) Almost always true of me: There are very few times when I don't feel this way.

\begin{tabular}{|c|c|c|c|c|c|c|}
\hline $\mathrm{S} / \mathrm{N}$ & Assessment statements & 1 & 2 & 3 & 4 & 5 \\
\hline 1. & $\begin{array}{l}\text { I'm looking forward to learning as long as I'm } \\
\text { living. }\end{array}$ & & & & & \\
\hline 2. & I know what I want to learn. & & & & & \\
\hline 3. & $\begin{array}{l}\text { When I see something that I don't understand, I } \\
\text { stay away from it. }\end{array}$ & & & & & \\
\hline 4. & $\begin{array}{l}\text { If there is something I want to learn, I can figure } \\
\text { out a way to learn it. }\end{array}$ & & & & & \\
\hline 5. & I love to learn. & & & & & \\
\hline 6. & It takes me a while to get started on new projects. & & & & & \\
\hline 7. & $\begin{array}{l}\text { In a classroom situation, I expect the instructor } \\
\text { to tell all class members exactly what to } \\
\text { do at all times. }\end{array}$ & & & & & \\
\hline 8. & $\begin{array}{l}\text { I believe that thinking about who you are, where } \\
\text { you are, and where you are going should be a } \\
\text { major part of every person's education. }\end{array}$ & & & & & \\
\hline 9. & I don't work very well on my own. & & & & & \\
\hline 10. & $\begin{array}{l}\text { If I discover a need for information that I don't } \\
\text { have, I know where to go to get it. }\end{array}$ & & & & & \\
\hline 11. & $\begin{array}{l}\text { I can learn things on my own better than most } \\
\text { people. }\end{array}$ & & & & & \\
\hline 12. & $\begin{array}{l}\text { Even if I have a great idea, I can't seem to } \\
\text { develop a plan for making it work. }\end{array}$ & & & & & \\
\hline 13. & $\begin{array}{l}\text { In a learning experience, I prefer to take part in } \\
\text { deciding what will be learned and how. }\end{array}$ & & & & & \\
\hline 14. & $\begin{array}{l}\text { Difficult study doesn't bother me if I'm } \\
\text { interested in something. }\end{array}$ & & & & & \\
\hline 15. & No one but me is truly responsible for what I learn. & & & & & \\
\hline 16. & $\begin{array}{l}\text { I can tell whether I'm learning something } \\
\text { well or not. }\end{array}$ & & & & & \\
\hline 17. & $\begin{array}{l}\text { There are so many things I want to learn that I wish } \\
\text { there were more hours in a day. }\end{array}$ & & & & & \\
\hline 18. & $\begin{array}{l}\text { If there is something I have decided to learn, I can } \\
\text { find time for it, no matter how busy I am. }\end{array}$ & & & & & \\
\hline 19. & Understanding what I read is a problem for me. & & & & & \\
\hline 20. & If I don't learn, it's not my fault. & & & & & \\
\hline
\end{tabular}




\section{Continued}

21. I know when I need to learn more about something.

If I can understand something well enough to get

22. by, it doesn't bother me if I still have questions about it.

23. I think libraries are boring places.

The people I admire most are always learning new things.

25. I can think of many different ways to learn about a new topic.

26.

I try to relate what I am learning to my long-term goals.

27. I am capable of learning for myself almost anything I might need to know.

28.

I really enjoy tracking down the answer to a question.

29. I don't like dealing with questions where there is not one right answer.

30. I have a lot of curiosity about things.

31. I'll be glad when I'm finished learning.

32. I'm not as interested in learning as some other people seem to be.

33. I don't have any problems with basic study skills.

34. I like to try new things, even if I'm not sure how they will turn out.

35. I don't like it when people who really know what they're doing point out mistakes that I am making.

36. I'm good at thinking of unusual ways to do things.

37. I like to think about the future.

38. I'm better than most people are at trying to find out the things I need to know.

39. I think of problems as challenges, not stop-signs.

40. I can make myself do what I think I should.

41. I'm happy with the way I investigate problems.

42. I become a leader in group learning situations.

43. I enjoy discussing ideas.

44. I don't like challenging learning situations.

45. I have a strong desire to learn new things.

46. The more I learn, the more exciting the world becomes.

47. Learning is fun

It's better to stick with the learning methods that

48. we know will work instead of always trying new ones. 


\section{Continued}
49. I want to learn more so that I can keep growing as a person.
50. I am responsible for my learning - no one else is.
51. Learning how to learn is important to me.
52. I will never be too old to learn new things.
53. Constant learning is a bore.
54. Learning is a tool for life.
55. I learn several new things on my own each year.
56. Learning doesn't make any difference in my life.
57. I am an effective learner in a classroom situation and on my own.
58. Learners are leaders.

Thank you.

Copyright (C) Lucy M. Guglielmino, 2008 